\title{
The challenge and future of rocky desertification control in karst areas in southwest China
}

\author{
J. Y. Zhang ${ }^{1,2}$, M. H. Dai ${ }^{1}$, L. C. Wang ${ }^{1}$, C. F. Zeng ${ }^{1}$, and W. C. Su ${ }^{3}$ \\ ${ }^{1}$ School of Geographic and Oceanographic Sciences, Nanjing University, Nanjing 210023, China \\ ${ }^{2}$ School of Tourism and Land Resources, Chongqing Technology and Business University, Chongqing 400067, China \\ ${ }^{3}$ The Institute of Mountain Resources, Guizhou Academy of Sciences, Guiyang 550018, China \\ Correspondence to: C. F. Zeng (zengchunfen@nju.edu.cn)
}

Received: 2 November 2015 - Published in Solid Earth Discuss.: 20 November 2015

Revised: 21 December 2015 - Accepted: 21 December 2015 - Published: 15 January 2016

\begin{abstract}
Karst rocky desertification occurs after vegetation deteriorates as a result of intensive land use, which leads to severe water loss and soil erosion and exposes basement rocks, creating a rocky landscape. Karst rocky desertification is found in humid areas in southwest China, the region most seriously affected by rocky desertification in the world. In order to promote ecological restoration and help peasants out of poverty, the Chinese government carried out the first phase of a rocky desertification control project from 2006 to 2015, which initially contained the expansion of rocky desertification. Currently, the Chinese government is prepared to implement the second phase of the rocky desertification control project, and therefore it is essential to summarise the lessons learned over the last 10 years of the first phase. In this paper, we analyse the driving social and economic factors behind rocky desertification, summarise the scientific research on rocky desertification in the region, and finally identify the main problems facing rocky desertification control. In addition, we put forward several policy suggestions that take into account the perspective of local peasants, scientific research, and China's economic development and urbanisation process. These suggestions include promoting the non-agriculturalization of household livelihoods, improving ecological compensation, strengthening the evaluation of rocky desertification control and dynamic monitoring, and strengthening research on key ecological function recovery technologies and supporting technologies.
\end{abstract}

\section{Introduction}

Karst rocky desertification (RD) is a term used to characterise the process that transforms a karst area covered by vegetation and soil into a bare rocky landscape almost devoid of soil and vegetation in fragile karst ecosystems in tropical and subtropical regions (Yuan, 1997; Wang et al., 2004a). In general, water loss and soil erosion take place when surface vegetation is destroyed, leading to land desertification (Barbero-Sierra et al., 2015; Torres et al., 2015; Cerdà and Lavee, 1999). Degraded land surface vegetation can gradually be restored and water loss and soil erosion can be reduced with timely management, leading to ecological recovery (Lovich and Bainbridge, 1999; Vieira et al., 2015). Unfortunately, this has not occurred in the karst areas of southwest China. Because of vegetation deterioration caused by unreasonable human activities, water loss and soil erosion have already taken place. This has caused bedrock to be exposed and has initiated a process similar to desertification (Fig. 1).

Once this process begins it is very difficult to reverse, and for this reason it has been called "the earth's cancer" by the Chinese media. Karst rocky desertification occurs mainly in southwest China in an area of $107.16 \times 10^{4} \mathrm{~km}^{2}$ and includes parts of the provinces of Guizhou, Yunnan, Sichuan, Guangxi, Guangdong, Hunan, Hubei, and the city of Chongqing (Table 1, Fig. 2). In addition to China, rocky desertification has also occurred in other regions in the world, such as the Mediterranean region, North America, southeast Asia, and some Caribbean island countries (Ford and Williams, 2007; Jiang et al., 2014; Sunkar, 2008; Williams, 2011; Symeonakis et al., 2014). 

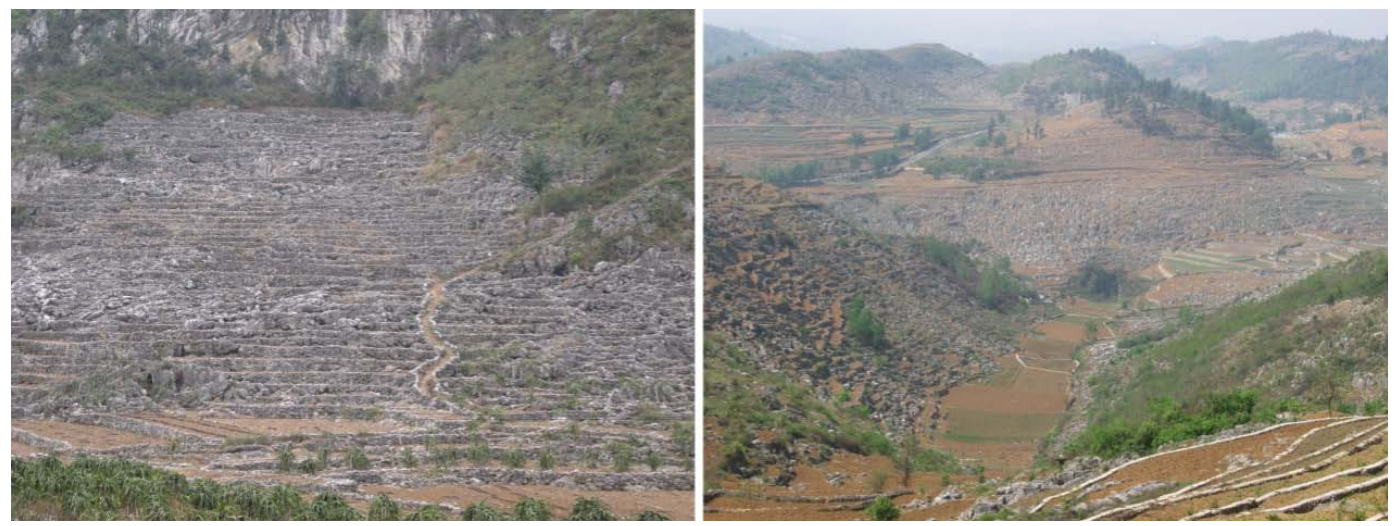

Figure 1. Karst rocky desertification in the karst area of southwest China (photograph location, left: Pingguo, Guangxi, right: Dafang, Guizhou).

Table 1. The current state of RD and potential rocky desertification (PRD) in 2012 and the change of RD from 2005 to 2012 in southwest China.

\begin{tabular}{lrrrrrrrr}
\hline Province & Guizhou & Yunnan & Guangxi & Hunan & Hubei & Chongqing & Sichuan & Guangdong \\
\hline RD area/10 4 ha & 302.4 & 284 & 192.6 & 143.1 & 109.1 & 89.5 & 73.2 & 6.3 \\
The proportion of RD area/\% & 25.2 & 23.7 & 16 & 11.9 & 9.1 & 7.5 & 6.1 & 0.5 \\
PRD area/10 4 ha & 325.6 & 237.8 & 229.4 & 177.1 & 156.4 & 87.1 & 76.9 & 41.5 \\
The proportion of RD area/\% & 24.5 & 17.9 & 17.2 & 13.3 & 11.7 & 6.5 & 5.8 & 3.1 \\
The change of RD area/104 ha & -29.23 & -4.16 & -45.29 & -4.81 & -3.4 & -3.04 & -4.31 & -1.76 \\
The change ratio of RD area/\% & -8.82 & -1.44 & -19.03 & -3.26 & -3.26 & -3.28 & -5.56 & -21.57 \\
\hline
\end{tabular}

Currently, the desertification control research in the world mainly focuses on arid and semi-arid areas (Cerdà and Lavee, 1999; Bisaro et al., 2014; Cerdà et al., 2009; De Pina Tavares et al., 2014; Escadafal et al., 2015; Fleskens and Stringer, 2014), but research on karst rocky desertification control is relatively scarce. However, the processes and control of karst rocky desertification are significantly different from desertification. The process of karst rocky desertification is nearly irreversible in a short time, such as the timescale of a decade, and so it could be argued that the damage resulting from rocky desertification is permanent. Rocky desertification has severely affected the local ecology, hydrology, and soils at various scales and is consequently responsible for droughts, floods, landslides, land subsidence, and other geological hazards. Rocky desertification not only degrades the ecological environment but also affects agricultural and forestry production, seriously hindering the sustainable development of the local socio-economy. The expansion of rocky desertification has put more strain on people's lives in these areas where they are already living below the poverty line (Yang et al., 2014).

In order to curb rocky desertification, promote ecological restoration, and help peasants out of poverty, the Chinese government carried out the first phase of a rocky desertification control project between 2006 and 2015, which initially contained the expansion of rocky desertification (Bai, et al., 2013). Although the area of rocky desertification has decreased by $96 \times 10^{4}$ ha, the work of RD control faces serious future challenges. As of 2012, there is still a rocky desertification area of $1200.02 \times 10^{4}$ ha and a potential rocky desertification (PRD) area of $1331.8 \times 10^{4}$ ha (the State Forestry Administration of the People's Republic of China, 2012). PRD refers to the landscape whose bedrock is carbonate rocks, and the degree of rock exposed is more than $30 \%$. The vegetation coverage is better (trees and shrubs coverage is over $50 \%$ or herbage coverage is over $70 \%$ ), but it is likely to evolve into rocky desertification land in the event of unreasonable human activities. The rocky desertification area is likely to continue to expand in the face of unreasonable human activities. The Chinese government is currently prepared to implement the second phase of the rocky desertification control project, so it is essential to summarise what has been learned from the first phase of the project. In this paper, we analyse the driving social and economic factors behind rocky desertification, summarise the scientific research on rocky desertification in the region, and finally identify the main problems facing rocky desertification control. In addition, we put forward several policy suggestions in the future rocky desertification control. 


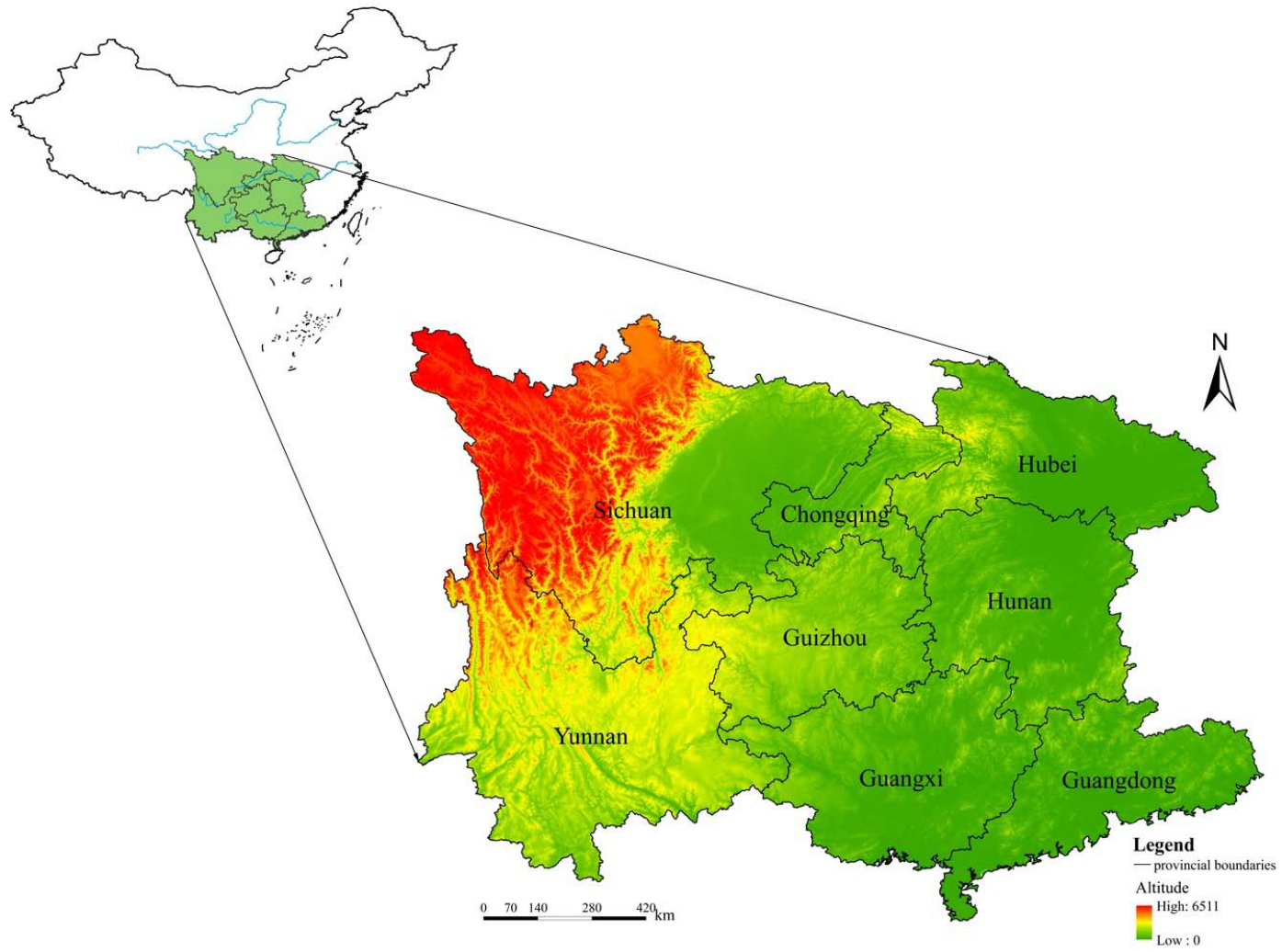

Figure 2. The main provinces of karst rocky desertification in southwest China.

\section{The relationship among rocky desertification, natural processes, and human activities}

Rocky desertification in southwest China owes its formation to the special geological and ecological environment of the region. Since it lies in a subtropical climate zone, it is warm and humid in summer, and cold in winter. It is rainy and the mean annual precipitation is $1000-1400 \mathrm{~mm}$, occurring mainly from May to September. The rainfall intensity is high, easily leading to water loss and soil erosion (Yuan, 2014). The mean annual temperature is $15-20^{\circ}$. Moreover, the carbonate rocks are highly soluble, leading to widespread distribution of karst sinkholes and karst fissure and broken and steep topography, which has increased water loss and soil erosion. Karstification is strong and forms the interlinking structure between the surface and underground, allowing surface water to leak easily. The stability of the vegetation system is poor. Generally, the vegetation has calciphilia, xeric and rock-grown characteristics, and low biomass. For example, the total biomass of the top forest communities in the Maolan karst region is 168.62 tons ha ${ }^{-1}$ (Zhang et al., 2015), only equal to the xerodrymium in the semi-arid areas of the subtropical zones. What is more, it is very sensitive to external disturbance and cannot be easily recovered in the event of damage. The soil layer is shallow and broken, and the soil formation rates are extremely slow. A similar analysis of 133 samples in Guizhou showed that forming $1 \mathrm{~cm}$ of soil would take 4 to 8.5 thousand years ( $\mathrm{Su}, 2002)$. The adhesive force between the overlying soil and the underlying bedrock is extremely low (Su and $\mathrm{Zhu}, 2000$ ), and is prone to soil erosion and rocky desertification caused by heavy rainfall. The water loss and soil erosion increase sharply with the increase of the slope gradient. The soil layer thickness and the soil erosion amount is around $86 \mathrm{~cm}$ and 3150 tons $\mathrm{km}^{-2}$ per year for slopes 20-25, and $71 \mathrm{~cm}$ and 11700 tons $\mathrm{km}^{-2}$ per year for slopes 30-35 (Jiang et al., 2014). Therefore, even with less human interference, rocky desertification would still occur in some areas. For example, Xiake $\mathrm{Xu}$, a Chinese ancient geographer, described that "there are mountains almost without any soil cover when entering Guizhou, especially in Guiyang" in the chapter "Guizhou Travel Dairy" from his book Xiake Xu Travel Notes in 1638 (Jiang et al., 2014).

Aside from geological and ecological factors, excessive human interference, especially intensive land use, is the main trigger for large-scale rocky desertification (Xu and Zhang, 2014; Jiang et al., 2014; Li et al., 2009; Yan and Cai, 2015; Yang et al., 2011; Ni et al., 2015). The vegetation has been seriously degraded by large-scale human activities since 1950, with initiatives such as the "Great Leap Forward (GLF)", the "Work for Food Program (WFP)", and others (Jiang et al., 2014; Wang et al., 2004b). The GLF and WFP were national movements in China between 1957 and 1960 when people 
blindly called for high economic development (production of iron) and agricultural production, leading to large-scale deforestation and serious environment degradation. In addition, karst areas are overpopulated and socio-economically backward. For example, the population growth rate of Guizhou was $12.58 \%$ o from 1978 to 2013 (The National Bureau of Statistics of China, 2015). This tension between people and land caused by overpopulation and land scarcity is severe (Fig. 3 and Table 2). It has forced peasants to reclaim wasteland and cultivate on steep slopes, which has become common in the karst areas in southwest China (Fig. 3); yet steep slopes are precisely the places most at risk of rocky desertification (Jiang et al., 2009). It is thus fair to conclude that backward economic development is the main cause of rocky desertification in the region (Bai et al., 2013); that is to say the excessive human interference due to backward economic development is the main cause of rocky desertification.

Similar to the situation in karst areas in China, in the Mediterranean, agriculture production and deforestation caused by unreasonable human activities (Kéfi et al., 2007), such as slash-and-burn cultivation and destroying forest for land reclamation, were major causes of rocky desertification. But the existing hillslopes were split into terraces by machines because the land prices were increasing. Grapes and other economic crops were planted instead of food crops with extensive machinery management. For example, bulldozers tore off epikarst from the ground into gravel, and then compacted it with added topsoil (Ford and Williams, 2007). Meanwhile, a strategy for the use of vegetation to combat rocky desertification and land degradation has been developed in the Mediterranean (Hooke and Sandercock, 2012). In short, rocky desertification in the Mediterranean is triggered by the special geological environment and excessive human interference, both of which have directly or indirectly affected water budgets and land degradation through associated changes in land use patterns. But in China, with increasing population and limited non-agricultural employment, labour in this region continues to be invested in cultivating limited land in order to increase land production, which has caused a decrease in households' marginal benefit and agricultural involution. With the continuous development of agricultural involution, the phenomena of over-exploitation, overgrazing, deforestation, and steep slope reclamation become increasingly serious, resulting in the degradation of the ecological environment, and finally triggering rocky desertification. In other words, the area has fallen into a vicious cycle of poverty and environmental degradation at different scales (Fig. 4).

\section{The challenges that are confronted with in rocky desertification control}

Rocky desertification control is carried out through the participation of the government, peasants, enterprises, and scientific researchers. It is a continuous process of coordinat- ing various multi-stakeholders for a common goal. Existing rocky desertification control practices are mainly driven by the government and the role of peasants is not significant. The achievement of rocky desertification control was hindered because various multi-stakeholders, such as the government, peasants, and enterprises, were overly concerned with their own interests (enterprises mainly have to carry out practical rocky desertification control planning according to the government's target, and to take measures to restore rocky desertification land). Furthermore, policies which aimed to achieve a common goal, such as the standards of planting density set by the government, were not effectively implemented because they lacked effective mechanisms to coordinate multi-stakeholders' interests. The construction of governance models was dominated by the government administration, research institutions, and enterprises. Although some good comprehensive benefits were achieved, some governance models were constructed without considering the current national economic situation. Economic development led to the outflow of the rural labour force and some governance models were overly dependent on external input, which could not be a sustainable development solution since it lacked supporting industries separate from national input (Zhang et al., 2014). Moreover, in the process of formulating rocky desertification governance models, peasants were mainly involved as builders and participants, but were excluded from any independent development of rocky desertification control. Furthermore, some governance models of rocky desertification control did not consider peasants' conditions and needs (Cai and Zhang, 2009), and therefore destroyed any incentive for peasant compliance, especially for those located out of the control demonstration area that were devoid of capital, technology, and other support.

The fundamental purpose of rocky desertification control is to maintain the limited soil and water resources, restore the vegetation and ecological environment, promote economic development, and help peasants out of poverty. With the development of China's economy, peasants' standards of living have greatly improved. Merely aspiring to feed and clothe themselves, they now aspire to earn greater income. For this reason, economic benefits have become decisive factors for their production activities. At present, peasants' income from rocky desertification control mainly comes from planting cash crops and from subsidies for converting farmland to forest and grassland. And the compensation standards and deadlines were made by every county and city according to their own conditions. Generally, the compensation time is no more than 3 years, or there is one-time monetary compensation. Therefore, peasants are likely to give up the management of desertification control when they receive insufficient income due to fluctuations in market prices (which easily affect benefits given from planting cash crops), low subsidies, and short compensation times. Therefore, the socio-economic factors that cause rocky desertification have not been eliminated. Meanwhile, the mechanisms and degree of impact of rocky 
Table 2. The current state of socio-economic development and rocky desertification (RD) in the main karst provinces in southwest China in 2012.

\begin{tabular}{lrrrrrr}
\hline District & $\begin{array}{r}\text { RD area } \\
\text { in } 10^{4} \text { ha }\end{array}$ & $\begin{array}{r}\text { Per capita cultivated } \\
\text { land in rural areas in ha }\end{array}$ & $\begin{array}{r}\text { Per capita } \\
\text { GDP in RMB }\end{array}$ & $\begin{array}{r}\text { Economic growth } \\
\text { rate in \% }\end{array}$ & $\begin{array}{r}\text { The proportion of } \\
\text { primary industry in \% }\end{array}$ & $\begin{array}{r}\text { The ratio of dependence } \\
\text { upon foreign trade in \% }\end{array}$ \\
\hline Guizhou & 302.4 & 0.079 & 19608 & 13.6 & 13 & 7.62 \\
Yunnan & 284 & 0.107 & 22263 & 13 & 16 & 15.9 \\
Guangxi & 192.6 & 0.091 & 27952 & 11.3 & 16.7 & 15.76 \\
China & 1200.2 & 0.156 & 38354 & 7.7 & 50.57 \\
\hline
\end{tabular}
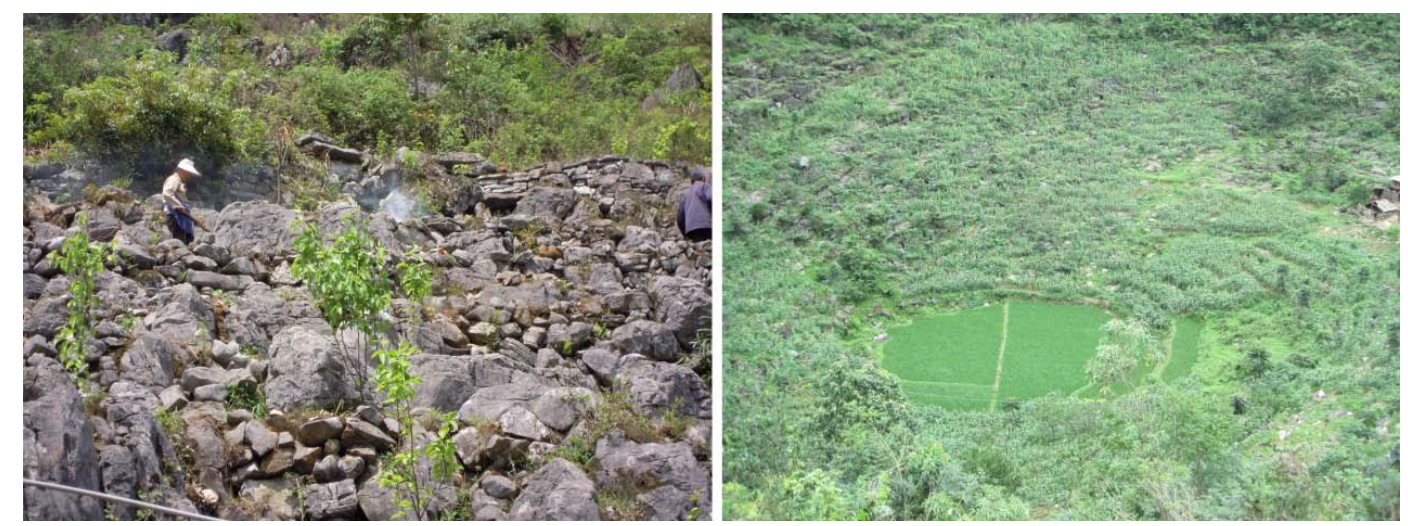

Figure 3. The peasants cultivated steep slopes in the karst areas in southwest China. Left: a peasant cultivating steep slopes in a karst area in southwest China, shot in Puding, Guizhou. Right: rice grows in the centre and corn on the surrounding slopes, shot in Pingtang, Guizhou.

desertification control on peasants' income are unclear due to a lack of quantitative research. Research results of similar ecological restoration projects, such as Sloping Land Conversion Program (SLCP), showed that the SLCP's direct impact on the income of participant households was insignificant. Instead, the increase of household income can be mainly attributed to the significant acceleration of the non-agricultural labour force (Li et al., 2011; Yin et al., 2014; Lin and Yao, 2014). Likewise, rocky desertification control has reduced the demand for agricultural labour and has promoted the transfer of agricultural surplus labour to non-agricultural employment (Xiao et al., 2012), which may have indirectly contributed to an increase of household income.

Control technologies are an extremely important part of rocky desertification control projects because they directly affect their effectiveness and peasants' willingness to participate in rocky desertification control. Although existing rocky desertification control technologies have achieved better vegetation restoration results (Bai et al., 2013), the vegetation system has not stabilised and is still prone to degradation (Zhang et al., 2015). There have been few studies conducted on the selection and breeding of recovery plants, collocation of plant species, and the ecological adaptation of plants to rocky desertification control technologies. Accordingly, control practices have tended to rely heavily on experience. For instance, restoration vegetation has been mainly composed of afforestation even though dense grasses signifi- cantly reduce soil erosion at lower costs and are widely available in a variety of natural environments (Peng et al., 2013); yet, grasses have not been widely promoted. Further research is also needed on the ecological effects of alien plants as well as the control effects of water use and supply technologies.

Most restoration projects have focused on vegetation recovery as a means of assessing the effectiveness of restoration (Young, 2000; Ruiz-Jaén and Aide, 2005), ignoring the recovery capacity of the ecosystem and its resilience to perturbation. At present, the assessment of rocky desertification control and restoration has focused on the economic benefits of governance models and technologies, as well as changes in soil erosion and the physicochemical properties of the soil (Tang et al., 2013; Xie et al., 2015), overlooking an assessment of governance efficiency. Moreover, there has been considerable arbitrariness in establishing evaluation systems and applying evaluation methods, which may consequently have led to the great range of evaluation results in the same area (Zhang et al., 2014). There is also a lack of quantitative data for evaluating ecosystem restoration after control measures have been implemented, such as to what extent the ecosystem should be maintained and managed, what kind of governance policies should be used in follow-up management, and how the health of the restored ecosystem should be monitored. This has caused the management and maintenance of rocky desertification control to fall behind. 


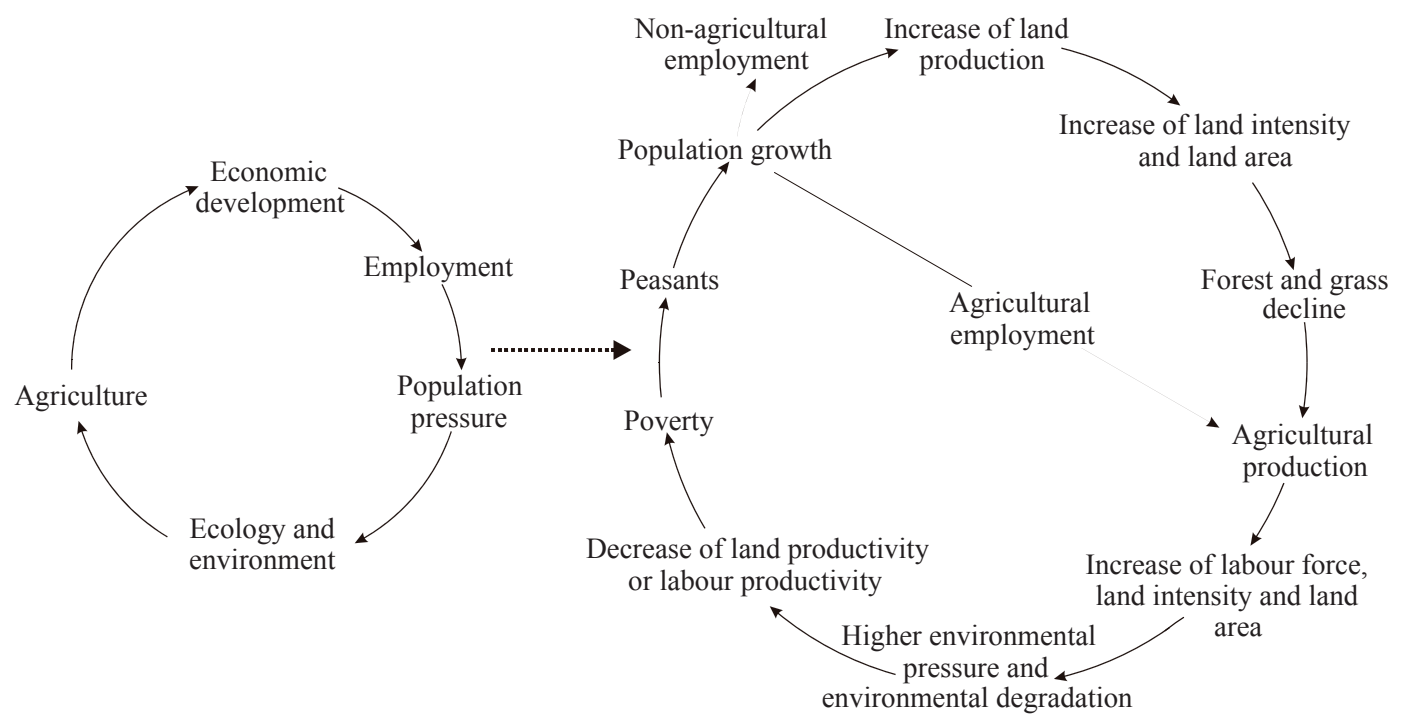

Figure 4. Multi-scale feedback relationship between land use and the ecosystem in the karst areas in southwest China.

In short, rocky desertification control is not only a scientific issue, but also a household livelihood issue (Wang and $\mathrm{Li}, 2007$ ), which should be addressed with governance methods and technologies, as well as the design of policies and public participation. Such an approach is imperative for future rocky desertification control initiatives.

\section{Future improvements of rocky desertification control}

\subsection{The promotion of the non-agriculturalization of household livelihoods}

The rural labour force outflow caused by China's rapid economic development made an important contribution to the recovery of the ecological environment (Wang et al., 2011). For example, in Guangxi in southwest China, the growth rate of rocky desertification area dramatically decreased during the period of rapid economic development (Liu et al., 2008). There is a clear trend of the rural labour force turning away from agriculture with sustainable industrialisation and rapid urbanisation ( $\mathrm{Li}, 2008)$. Currently, there has been a halt in the expansion of cultivated land, along with largescale de-intensification and abandonment of cultivated land (Ge et al., 2012), which has helped to restore the local ecological environment. The Chinese government has set developing economic zones in the midlands of Guizhou and Yunnan in 2014. We should therefore seize the opportunity to further promote the non-agricultural migration of household livelihoods and accelerate the non-agricultural outflow of the rural labour force, while focusing on improving local non-agricultural employment and relocating people for nonagricultural work. It is also the key to break the vicious cycle of poverty and environmental degradation at different scales.

\subsection{The improvement of ecological compensation policies and establish coordination mechanisms of multi-stakeholders in rocky desertification control}

The household livelihood concerns of peasants have changed from maintaining livelihood security to pursuing higher profits. However, with more and more attention being paid to the effects of rocky desertification control on improving local ecosystem services, the private goods function of rocky desertification control is decreasing while its function as a public goods is increasing. Therefore, the biggest beneficiaries of rocky desertification control are the users of the products, not just the peasants. But as the implementers of rocky desertification control, peasants' prime consideration is their own utility maximisation which is not equal to the overall utility maximisation. Therefore, the evaluation standards for utility maximisation of rocky desertification control should be made on the basis of all users of the products, not just the peasants. In order to achieve the goal of utility maximisation of rocky desertification control, ecological compensation should be provided for participant peasants and appropriately increased with the development and inflation of socio-economy. In order to achieve the sustainability of the joint action of various multi-stakeholders, to clarify the needs of various participants, and to move away from sole government management, a rational coordination mechanism must be established to coordinate the interests of various participants. In order to coordinate the interests of various multistakeholders and achieve the economic, social, and ecological benefits of rocky desertification control, we should attempt to establish a management mechanism based on integrated ecosystem management methods. 


\subsection{The improvement of the evaluation system for evaluating the effectiveness of rocky desertification control and the strengthening of monitoring and dynamic evaluation}

A thorough evaluation system is the foundation of implementing ecological compensation and assessing the efficiency of rocky desertification control. Towards the end of improving the evaluation system, it should be noted that what crucially keeps ecosystems running sustainably are vegetation structure, biodiversity, and ecosystem processes, all of which are essential components of the long-term survival of an ecosystem (Dorren et al., 2004). Furthermore, some recovery indicators based on key ecosystem functions should be established to achieve the recovery of ecosystem functions, such as the degree of biodiversity, the structure and complexity of trophic levels, and particularly, litter production and turnover. According to the different degrees of rocky desertification and control objectives in different types of karst geomorphology, we should correspondingly select appropriate reference ecosystems for evaluation and set up a relatively complete evaluation system. In the construction of the evaluation index system, except for directly considering economic benefits, we should also consider the different impacts of rocky desertification control on ecological security and ecological service functions, so as to establish reasonable ecological compensation standards and follow-up governance policies. It should be noted that economic values are not natural attributes of the ecosystem but are closely associated with the number of beneficiaries and their socioeconomic background. That also implies that, in general, the balance of ecosystem values in a certain region can only be extrapolated to those in similar regions; otherwise, adjustments must be made. In addition, ecosystem restoration is a slow and dynamic process, and there are significant uncertainties for ecosystem development in the recovery process (Bark et al., 2013). Thus, the dynamic monitoring of rocky desertification control is conducive to identifying problems and taking timely corrective measures.

\subsection{The strengthening of research on key recovery technologies of ecological service function and supporting technologies}

The special geological and ecological environment poses a great challenge to the restoration of degraded ecosystems in karst areas (Gillieson et al., 1996). With regards to research on ecological service function recovery technologies in degraded ecosystems in karst areas, we should focus on specific experimental verification techniques of ecological restoration based on different types of geography and climate zones. Since it is difficult to spontaneously recover the structure and functions of a degraded karst ecosystem, (such as the storage capacity of epikarst, land productivity, and the natural resilience of vegetation), we should also focus on studying the vital supporting technologies of rocky desertification control, such as storage technology for surface water resources, exploitation and utilization technologies for underground water resources, the selection and breeding of special economic and ecological recovery plants, and optimal configuration technologies and models of adaptive plant communities.

\section{Conclusions}

Soil and water conservation in karst ecosystems is one of the fundamental goals of rocky desertification control and is the foundation of local, social, and economic development, especially for peasants. In the process of vigorously implementing rocky desertification control, we must pay close attention to the following two facts: first, the environmental consequences of the same human activities in the karst area in southwest China are far heavier than that in similar climate zones because of its special geological and ecological environment; second, the resilience of karst ecosystems is far lower than that in similar climate zones, and so it is very difficult for the ecological system to recover from destruction caused by unreasonable human activities. Thus, in order to improve rocky desertification control, we should focus more on eliminating the anthropic factors causing rocky desertification in institutions, policies, and the economy, and on strengthening preventative measures for ecological degradation. In particular, we must deviate from the existing administrative department framework, which has been divided according to ecosystem elements (e.g. the Forestry Bureau is responsible for forests and the Water Resource Bureau is responsible for water loss and soil erosion), and create policy frameworks that reflect administrative divisions. More importantly, we should formulate regulations and policies according to ecosystem integrity and geographical regions in order to improve this ubiquitous phenomenon, since governance management of rocky desertification control so far has not been that successful.

In addition, climate warming has severely affected karst ecosystems, such as water resources (Lian et al., 2015; Thomas et al., 2016). Climate warming has an impact on regional precipitation, evaporation, and runoff. Besides, it will increase extreme weather events, such as heavy rainfall, high temperature, and drought etc., coupled with serious seepage of surface water, easily leading to regional vegetation degradation and the increase of soil erosion. Therefore, we should strengthen research on the impact of global climate change on rocky desertification control.

\section{Data availability}

The data of Tables $1 \& 2$ are acquired from the Bulletin of Rocky Desertification in China 2012 and China Statistical Yearbook 2013; the photographs in Figs. 1 \& 3 were shot by the author in his field investigation. 
Acknowledgements. This work was partially supported by the National Natural Science Foundation of China (no. 41371045), the National Social Science Foundation of China (no. 13CJY067), and the Major Applied Basic Programs of Guizhou Province (no. JZ-2014-200206).

Edited by: A. Cerdà

\section{References}

Bai, X. Y., Wang, S. J., and Xiong, K. N.: Assessing spatialtemporal evolution processes of karst rocky desertification land: indications for restoration strategies, Land Degrad. Dev., 24, 4756, doi:10.1002/ldr.1102, 2013.

Barbero-Sierra, C., Marques, M. J., Ruiz-Pérez, M., Escadafal, R., and Exbrayat, W.: How is Desertification Research Addressed in Spain? Land Versus Soil Approaches, Land Degrad. Dev., 26, 423-432, doi:10.1002/ldr.2344, 2015.

Bark, R. H., Peeters, L. J. M., Lester, R. E., Pollino, C. A., Crossman, N. D., and Kandulu, J. M.: Understanding the sources of uncertainty to reduce the risks of undesirable outcomes in large-scale freshwater ecosystem restoration projects: An example from the Murray-Darling Basin, Australia, Environ. Sci. Policy, 33, 97-108, doi:10.1016/j.envsci.2013.04.010, 2013.

Bisaro, A., Kirk, M., Zdruli, P., and Zimmermann, W.: Global drivers setting desertification research priorities: Insights from a stakeholder consultation forum, Land Degrad. Dev., 25, 5-16, doi:10.1002/ldr.2220, 2014.

Cai, S. Q. and Zhang, B. L.: Discussion on the Integrated Ecosystem Management and Rocky Desertification Control, Journal of Fujian College of Political Science \& Law, 42, 26-31, 2009.

Cerdà, A. and Lavee, H.: The effect of grazing on soil and water losses under arid and mediterranean climate, Implications for desertification, Pirineos, 153-154, 159-174, doi:103989/pirineos.1999.v153-154.111, 1999.

Cerdà, A., Morera, A. G., and Bodí, M. B.: Soil and water losses from new citrus orchards growing on sloped soils in the western Mediterranean basin, Earth Surf. Proc. Land., 34, 1822-1830, doi:10.1002/esp.1889, 2009.

De Pina Tavares, J., Ferreira, A. J. D., Reis, E. A., Baptista, I., Amoros, R., Costa, L., Furtado, A. M., and Coelho, C.: Appraising and selecting strategies to combat and mitigate desertification based on stakeholder knowledge and global best practices in cape verde archipelago, Land Degrad. Dev., 25, 45-57, doi:10.1002/ldr.2273, 2014.

Dorren, L. K. A., Berger, F., Imeson, A. C., Maier, B., and Rey, F.: Integrity, stability and management of protection forests in the European Alps, Forest Ecol. Manage., 195, 165-176, doi:10.1016/j.foreco.2004.02.057, 2004.

Escadafal, R., Barbero-Sierra, C., Exbrayat, W., Marques, M. J., Akhtar-Schuster, M., El Haddadi, A., and Ruiz, M.: First Appraisal of the Current Structure of Research on Land and Soil Degradation as Evidenced by Bibliometric Analysis of Publications on Desertification, Land Degrad. Dev., 26, 413-422, doi:10.1002/ldr.2351, 2015.

Fleskens, L. and Stringer, L. C.: Land management and policy responses to mitigate desertification and land degradation, Land Degrad. Dev., 25, 1-4, doi:10.1002/1dr.2272, 2014.
Ford, D. C. and Williams, P.: Karst Hydrogeology and Geomorphology, Wiley, Chichester, UK, 2007.

Ge, L., Gao, M., Hu, Z. F., and Han, X. F.: Reasons of cultivated land abandonment in mountainous area based on farmers' perspective, Chinese Journal of Agricultural Resources and Regional Planning, 33, 42-46, 2012 (in Chinese).

Gillieson, D., Wallbrink, P., and Cochrane, A.: Vegetation change, erosion risk and land management on the Nullarbor Plain, Australia, Environ. Geol., 28, 145-153, 1996.

Hooke, J. and Sandercock, P.: Use of vegetation to combat desertification and land degradation: Recommendations and guidelines for spatial strategies in Mediterranean lands, Landscape and Urban Planning, 107, 389-400, doi:10.1016/j.landurbplan.2012.07.007, 2012.

Jiang, Y. J., Li, L. L., Groves, C., Yuan, D. X., and Kambesis, P.: Relationships between rocky desertification and spatial pattern of land use in typical karst area, Southwest China, Environ. Earth Sci., 59, 881-890, doi:10.1007/s12665-009-0083-8, 2009.

Jiang, Z. C., Lian, Y. Q., and Qin, X. Q.: Rocky desertification in Southwest China: Impacts, causes, and restoration, Earth-Sci. Rev., 132, 1-12, doi:10.1016/j.earscirev.2014.01.005, 2014.

Kéfi, S., Rietkerk, M., Alados, C. L., Pueyo, Y., Papanastasis, V. P., ElAich, A., and de Ruiter, P. C.: Spatial vegetation patterns and imminent desertification in Mediterranean arid ecosystems, Nature, 449, 213-217, doi:10.1038/nature06111, 2007.

Li, J., Feldman, M. W., Li, S., and Daily, G. C.: Rural household income and inequality under the Sloping Land Conversion Program in western China, P. Natl. Acad. Sci. USA, 108, 77217726, doi:10.1073/pnas.1101018108, 2011.

Li, X. B.: Theoretical hypotheses about agricultural land use changes and the relevant propositions about environmental impacts, Advances in Earth Science, 23, 1124-1129, 2008 (in Chinese).

Li, Y. B., Shao, J. A., Yang, H., and Bai, X. Y.: The relations between land use and karst rocky desertification in a typical karst area, China, Environ. Geol., 57, 621-627, doi:10.1007/s00254008-1331-z, 2009.

Lian, Y., You, G. J., Lin, K., Jiang, Z., Zhang, C., and Qin, X.: Characteristics of climate change in southwest China karst region and their potential environmental impacts, Environ. Earth Sci., 74, 937-944, doi:10.1007/s12665-014-3847-8, 2015.

Lin, Y. and Yao, S. B.: Impact of the Sloping Land Conversion Program on rural household income: An integrated estimation, Land Use Policy, 40, 56-63, doi:10.1016/j.landusepol.2013.09.005, 2014.

Liu, Y. S., Wang, J. Y., and Deng, X. Z.: Rocky land desertification and its driving forces in the karst areas of rural Guangxi, Southwest China, J. Mountain Sci., 5, 350-357, doi:10.1007/s11629008-0217-6, 2008.

Lovich, J. E. and Bainbridge, D.: Anthropogenic Degradation of the Southern California Desert Ecosystem and Prospects for Natural Recovery and Restoration, Environ. Manage., 24, 309-326, 1999.

Ni, J., Luo, D. H., Xia, J., Zhang, Z. H., and Hu, G.: Vegetation in karst terrain of southwestern China allocates more biomass to roots, Solid Earth, 6, 799-810, doi:10.5194/se-6-799-2015, 2015.

Peng, J., Xu, Y. Q., Zhang, R., Xiong, K. N., and Lan, A. J.: Soil erosion monitoring and its implication in a limestone land 
suffering from rocky desertification in the Huajiang Canyon, Guizhou, Southwest China, Environ. Earth Sci., 69, 831-841, doi:10.1007/s12665-012-1968-5, 2013.

Ruiz-Jaén, M. C. and Aide, T. M.: Vegetation structure, species diversity, and ecosystem processes as measures of restoration success, Forest Ecol. Manage., 218, 159-173, doi:10.1016/j.foreco.2005.07.008, 2005.

$\mathrm{Su}$, W. C.: Controlling model for rocky desertification of karst mountainous region and its preventing strategy in Southwest China, Journal of Soil and Water Conservation, 16, 29-32, 2002 (in Chinese).

$\mathrm{Su}$, W. C. and Zhu, W. X.: The eco-environmental fragility in karst mountain regions of Guizhou province, J. Mountain Sci., 18, 429-434, 2000 (in Chinese).

Sunkar, A.: Deforestation And Rocky Desertification Processes In Gunung Sewu Karst Landscape (Proses Deforestasi dan Rocky Desertifcation di Landskap Karst Gunung Sewu), Media Konservasi, 13, 1-7, 2008.

Symeonakis, E., Karathanasis, N., Koukoulas, S., and Panagopoulos, G.: Monitoring sensitivity to land degradation and desertification with the environmentally sensitive area index: The case of lesvos island, Land Degrad. Dev., first published online, doi:10.1002/ldr.2285, 2014.

Tang, Y. Q., Li, J., Zhang, X. H., Yang, P., Wang, J. X., and Zhou, N. Q.: Fractal characteristics and stability of soil aggregates in karst rocky desertification areas, Natural Hazards, 65, 563-579, doi:10.1007/s11069-012-0383-2, 2013.

The National Bureau of Statistics of China: Guizhou Statistical Yearbook-2014, China Statistics Press, Beijing, China, 2015 (in Chinese).

The State Forestry Administration of the People's Republic of China: The Bulletin of rocky desertification in China, Beijing, China, 2012 (in Chinese).

Thomas, D., Johannes, K., David, K., Rüdiger, G., and Ralf, K.: Impacts of management and climate change on nitrate leaching in a forested karst area, J. Environ. Manag., 165, 243-252, doi:10.1016/j.jenvman.2015.09.039, 2016.

Torres, L., Abraham, E. M., Rubio, C., Barbero-Sierra, C., and Ruiz-Pérez, M.: Desertification Research in Argentina, Land Degrad. Dev., 26, 433-440, doi:10.1002/ldr.2392, 2015.

Vieira, R. M. S. P., Tomasella, J., Alvalá, R. C. S., Sestini, M. F., Affonso, A. G., Rodriguez, D. A., Barbosa, A. A., Cunha, A. P. M. A., Valles, G. F., Crepani, E., de Oliveira, S. B. P., de Souza, M. S. B., Calil, P. M., de Carvalho, M. A., Valeriano, D. M., Campello, F. C. B., and Santana, M. O.: Identifying areas susceptible to desertification in the Brazilian northeast, Solid Earth, 6, 347-360, doi:10.5194/se-6-347-2015, 2015.

Wang, C. C., Yang, Y. S., and Zhang, Y. Q.: Economic Development, Rural livelihoods, and Ecological Restoration: Evidence from China, AMBIO, 40, 78-87, doi:10.1007/s13280-010-00935, 2011.

Wang, S. J. and Li, Y. B.: Problems and development trends about researches on karst rocky desertification, Adv. Earth Sci., 22, 573-582, 2007.

Wang, S. J., Li, R. L., Sun, C. X., Zhang, D. F., Li, F. Q., Zhou, D. Q., Xiong, K. N., and Zhou, Z. F.: How types of carbonate rock assemblages constrain the distribution of karst rocky desertified land in Guizhou Province, PR China: phenomena and mech- anisms, Land Degrad. Dev., 15, 123-131, doi:10.1002/ldr.591, 2004a.

Wang, S. J., Liu, Q. M., and Zhang, D. F.: Karst rocky desertification in southwestern China: geomorphology, landuse, impact and rehabilitation, Land Degrad. Dev., 15, 115-121, doi:10.1002/ldr.592, 2004b.

Williams, V. J.: A case study of the desertification of Haiti, J. Sust. Develop., 4, 20-31, doi:10.5539/jsd.v4n3p20, 2011.

Xiao, J. Y., Xiong, K. N., Luo, Y., and Liu, L. C.: Effect of Ecological Construction on Rural Households' Economic Behavior in Rocky Desertification Area: Taking Huajiang demonstration area for example, Guizhou Agricultural Sciences, 40, 187-191, 2012 (in Chinese).

Xie, L. W., Zhong, J., Chen, F. F., Cao, F. X., Li, J. J., and Wu, L. C.: Evaluation of soil fertility in the succession of karst rocky desertification using principal component analysis, Solid Earth, 6, 515-524, doi:10.5194/se-6-515-2015, 2015.

$\mathrm{Xu}$, E. Q. and Zhang, H. Q.: Characterization and interaction of driving factors in karst rocky desertification: a case study from Changshun, China, Solid Earth, 5, 1329-1340, doi:10.5194/se5-1329-2014, 2014.

Yan, X. and Cai, Y. L.: Multi-Scale Anthropogenic Driving Forces of Karst Rocky Desertification in Southwest China, Land Degrad. Dev., 26, 193-200, doi:10.1002/ldr.2209, 2015.

Yang, Q. Q., Wang, K. L., Zhang, C. H., Yue, Y. M., Tian, R. C., and Fan, F. D.: Spatio-temporal evolution of rocky desertification and its driving forces in karst areas of Northwestern Guangxi, China, Environ. Earth Sci., 64, 383-393, doi:10.1007/s12665010-0861-3, 2011.

Yang, Q. Y., Jiang, Z. C., Yuan, D. X., Ma, Z. L., and Xie, Y. Q.: Temporal and spatial changes of karst rocky desertification in ecological reconstruction region of Southwest China, Environ. Earth Sci., 72, 4483-4489, doi:10.1007/s12665-014-3348-9, 2014

Yin, R. S., Liu, C., Zhao, M. J., Yao, S. B., and Liu, H.: The implementation and impacts of China's largest payment for ecosystem services program as revealed by longitudinal household data, Land Use Policy, 40, 45-55, doi:10.1016/j.landusepol.2014.03.002, 2014.

Young, T. P.: Restoration ecology and conservation biology, Biol. Conserv., 92, 73-83, doi:10.1016/S0006-3207(99)00057-9, 2000.

Yuan, D. X.: Rock desertification in the subtropical karst of south China, Zeitschrift fur Geomorphologie, 108, 81-90, 1997.

Yuan, D. X.: A study of significant environmental geological problems in Southwest karst areas in China, Science Press, Beijing China, 2014 (in Chinese).

Zhang, J. Y., Dai, M. H., Wang, L. C., and Su, W. C.: Rocky desertification control issues inthe context of priority for ecological function in karst areas of southwest China, Cardiologica Sinica, 33, 464-472, 2014 (in Chinese).

Zhang, J. Y., Dai, M. H., Wang, L. C., Su, W. C., and Cao, L. G.: Plant Selection and Their Ecological Adaptation for Rocky Desertification Control in Karst Region in the Southwest of China, Earth Environ., 43, 269-278, 2015 (in Chinese). 